\title{
CAUSES OF BLINDNESS IN VISUALLY DISABLED PERSONS IN BELAGAVI TALUK
}

\author{
Navalgund Surekha1, Sandeep Babasaheb Patil ${ }^{2}$
}

${ }^{1}$ Associate Professor, Department of Ophthalmology, Belagavi Institute of Medical Sciences, Belagavi.

${ }^{2}$ Senior Resident, Department of Ophthalmology, Belagavi Institute of Medical Sciences, Belagavi.

\section{ABSTRACT}

\section{BACKGROUND}

The purpose of this study is to study the causes of blindness in visually disabled persons of Belagavi taluk attended ophthalmology OPD at BIMS during 2013 - 2014.

\section{MATERIALS AND METHODS}

All patients with visual disability attended Ophthalmology OPD at BIMS during the year 2013 - 2014 are examined for distant vision with Snellen's chart. Ophthalmic examination includes anterior segment, slit lamp and fundus examination. Blindness defined as BCVA of $<3 / 60$ and visual fields $<10^{0}$ in better eye.

\section{RESULTS}

Total 222 persons (Male and Female) of all age group were examined. Blindness was avoidable in 49 (22\%) due to cataract and its complications and 36 cases with refractive errors (16\%). Others are posterior segment (RP, RD and optic atrophy), corneal and traumatic and congenital causes.

\section{CONCLUSION}

Majority of the disabled persons with cataract and its complications and refractive error. These can be prevented by means of awareness programme.

\section{KEYWORDS}

Cataract, Visual Disability, Avoidable/Preventable Blindness.

HOW TO CITE THIS ARTICLE: Surekha N, Patil SB. Causes of blindness in visually disabled persons in Belagavi Taluk. J. Evolution Med. Dent. Sci. 2017;6(23):1917-1919, DOI: 10.14260/Jemds/2017/420

\section{BACKGROUND}

Disability from blindness being major health problem in India. Rural population is the most vulnerable due to lack of awareness and poverty. Magnitude of blindness and its causes can be estimated by assessing visually impaired in rural population. The preventable causes for blindness was found high in rural population. By giving due service, timely help with Eye care services. There are numerous ocular ailments, which accounts to visual disability.

As per recent population based data, global estimation of visual impairment in year 2013 - 2014 is 324 million. In India, it is 8 million of all age groups. ${ }^{1}$ Prevalence rate is found higher in rural, then urban as per survey conducted in other states. ${ }^{2}$ This study was planned to find the cause of blindness among underprivileged population. So that we can achieve and contribute to the broad objectives of vision 2020 (The right to sight). As per WHO reports total number of blind persons in India was around 8.9 million in 1990, which was reduced to 6.7 million in 2002. There was a genuine reduction in the avoidable causes. In order to prevent the causes of avoidable blindness, various programmes have been launched to control blindness.

Financial or Other, Competing Interest: None.

Submission 10-02-2017, Peer Review 04-03-2017,

Acceptance 13-03-2017, Published 20-03-2017.

Corresponding Author:

Dr. Navalgund Surekha,

Plot No. 236, Ist Stage,

Hanuman Nagar,

Belagavi-590019

E-mail: navalgundsurekha@gmail.com

DOI: $10.14260 /$ jemds $/ 2017 / 420$

\section{They are-}

1. National programme for control of blindness [1976].

2. World Bank funded cataract surgery programme [1989 1990].

3. School Health Programme.

4. Private and NGO coordinated cataract camps.

5. Vision 2020 [Right to sight] Programme.

6. Awareness creation among rural population in coordination with Eye Bank.

7. i.e. Prevention of corneal blindness by Eye Bank establishment.

This study is conducted to know the causes of blindness among visually disabled people in BIMS Hospital during year 2013 - 2014 in Belagavi rural (Taluk) population.

\section{MATERIALS AND METHODS}

Belagavi taluk in Karnataka was selected being in Maharashtra border, where illiteracy and poverty prevails. The main occupation is agriculture, which accounts for corneal and cataract related complications.

It is a retrospective study designed to assess the causes of blindness. This study included all persons attending Ophthalmology OPD for disability certificate (Confirmed cases) at BIMS Hospital, Belgaum during the year 2013 - 2014. All age group persons with visual disability are included in this study. Total number of 222 persons attended to ophthalmology OPD are examined by ophthalmologist on duty for disability certificate at BIMS during the year 2013 - 2014. They all underwent complete ocular examination which includes-

- Visual acuity by Snellen's chart (either digits or E chart).

- Slit lamp examination to assess anterior segment. 
- Refraction testing (Retinoscopy, Subjective) in school going children.

- Fundus examination after pupillary dilatation.

- If needed USG and B scan was also done.

The preventable (treatable) cause was given precedence over a non-preventable (non-treatable) cause. The list of diagnoses included cataract and its complications, refractive error, cornea, posterior segment and congenital causes.

Blindness was defined using WHO criteria as BCVA of $<$ $3 / 60$ and visual field $<10^{\circ}$ in better Eye.

\section{RESULTS}

Total number of patients examined, diagnosed visually disabled are 222, of all age groups at BIMS during the year 2013 - 2014. After doing complete ocular examination, causes of blindness was diagnosed with priority as follows.

Out of 222 patients 137 were male, 85 were female. Gender disparities and poor access to services in rural area are still a challenge in India. It has been reported in the present study male being higher due to accessibility to disability centre.

Blindness was found bilaterally in 177 patients, while 45 patients had unilateral blindness.

Disability was found in majority in 20 to 30 age group (52) followed by 10 to 20 age group (51). The least number of cases fall in the age group of 0 - 10 years (05). The prevalence of blindness among those above 50 to 60 years is lower than 20 to 50 years' age group. Least number of causes are found in 0 to 10 years' age group are due to congenital cause.

With regard to percentage of disability, $100 \%$ was found in 146 patients followed by $30 \%$ to $40 \%$ found in 46 patients; 30 patients had $75 \%$ of disability. As per Central/State Government protocol - 100\% - F.C. at $1 \mathrm{ft}$ to Nil or field of vision $10^{0}$ in better eye and F.C. at $1 \mathrm{ft}$ to $\mathrm{Nil}$ in worse eye.

$75 \% 6 / 40-4 / 60$ or field of vision $10^{0}-20^{0}$ in better eye, $3 / 60$ to Nil in worse eye.

$30 \%$ with $6 / 6$ in better eye and F.C. at $1 \mathrm{ft}$ to Nil or field of vision $10^{0}$ in worse eye.

Among 222 patients, 49 patients were found visually disabled due to cataract and its complications. The cataract surgeries conducted at rural places are found with complications like aphakia, complicated pseudophakia, very few with retinal detachment. Majority are elderly (37) with complications and few children (12) with congenital/developmental cataract,(1) as the children are not diagnosed timely and attended surgically landed of into amblyopia.

The refractive error is the second most cause for disability,(2) i.e. uncorrected errors with amblyopia 36 (16\%). Though the child is diagnosed for having refractive error in school health programme, is not corrected with glasses or late diagnosis causing amblyopia in few children. Myopia with its complications was added for the prevalence.

Posterior segment causes 36 (16\%); includes diabetic retinopathy, retinitis pigmentosa and myopic fundus are found in 26 cases, while very few due to retinal detachment (3) and optic atrophy (7).

The corneal blindness was found in 33 persons $(15 \%)^{(3)}$ following trauma and infection, who are not attended by ophthalmologist.
Traumatic causes due to blunt trauma and post-operative (rural camps) were found in 33 persons. Out of them 27 were elderly, 6 were children.

Congenital causes like Microcornea, Microphthalmos, Coloboma constitutes 32 cases (14\%).

\begin{tabular}{|c|c|}
\hline Male & Female \\
\hline 137 & 85 \\
\hline \multicolumn{2}{|c|}{ Sex } \\
\hline
\end{tabular}

\begin{tabular}{|c|c|}
\hline Age & No. of Disabled \\
\hline $0-10$ & 05 \\
\hline $10-20$ & 51 \\
\hline $20-30$ & 52 \\
\hline $30-40$ & 38 \\
\hline $40-50$ & 30 \\
\hline $50-60$ & 23 \\
\hline $60-70$ & 16 \\
\hline 70 \& Above Age Group \\
\hline \multicolumn{2}{|c|}{07} \\
\hline \multicolumn{2}{|c}{} \\
\hline
\end{tabular}

\begin{tabular}{|c|c|}
\hline Unilateral & Bilateral \\
\hline 45 & 177 \\
\hline \multicolumn{2}{|c|}{ Laterality } \\
\hline
\end{tabular}

\begin{tabular}{|c|c|}
\hline $75-100 \%$ & 146 \\
\hline $50-75 \%$ & 30 \\
\hline $30-40 \%$ & 46 (Uniocular) \\
\hline \multicolumn{2}{|c|}{ Percentage of Disability } \\
\hline
\end{tabular}

\begin{tabular}{|c|c|c|}
\hline Causes for Disability & Numbers & Percentage \\
\hline Cataract and its Complications & 49 & $22 \%$ \\
\hline Refractive Error & 36 & $16 \%$ \\
\hline Posterior Segment Causes & 36 & $16 \%$ \\
\hline Corneal Blindness & 33 & $15 \%$ \\
\hline Traumatic Causes & 33 & $15 \%$ \\
\hline Congenital Causes & 32 & $14 \%$ \\
\hline $\begin{array}{c}\text { Others (Keratoconus } \\
\text { and SJ Syndrome) }\end{array}$ & 03 & $2 \%$ \\
\hline \multicolumn{2}{|c|}{ Total 222 } \\
\hline
\end{tabular}

\section{DISCUSSION}

Blindness is an important public health problem in India. To reduce the blindness burden among rural populationavoidable causes are to be tackled by visual awareness, early detection and timely surgical intervention.

Cataract is the major avoidable cause for visual blindness. We need to strengthen the blindness control programme effectively with skilled and dedicated workers, which in turn reduces burden of its complications. Hence, rural population has to be surveyed by local medical personal regularly and refer the same to operating centre. Decline in cataract blindness can be achieved by enhanced cataract surgery with no or few complications by skilled, trained, dedicated workers by reducing cataract related complication so that we can minimise disability prevalence. Cataract continues to be the commonest cause in India. The estimation found in SubSaharan Africa 35\%.(4) Recent studies from Maharashtra tribal,(5) coastal strip in Sindhdurga District(6) also shows cataract as a leading cause. Non-affordability, not accessible and having none to accompany are some of the significant barriers. 
Refractive error is being the second major cause ${ }^{(2)}$ with or without amblyopia and myopic complications. So regular school health programme and awareness creations, which helps to diagnose early and treat which in turn reduces its complications.

Posterior segment causes like diabetic retinopathy can be reduced by early diagnosis and regular followup. Timely intervention with laser treatment if necessary. Each and every person with diabetes should attend D-R Clinic and follow as per (ETDRS) early treatment diabetic retinopathy study guidelines. The prevalence of blindness due to diabetic retinopathy is increasing(1) - may be due to referral and detailed posterior examination at D-R Clinic.

The age standardised prevalence of blindness decreased substantially from 1990 to 2010.4 The avoidable causes of blindness like cataract and its complications (22), Refractive error (16\%). Posterior segment causes (16\%) mainly DR, corneal blindness (15\%), constitutes (69\%)- compared to 88.02 in RAAB (Rapid Assessment of Avoidable Blindness) in Indian study.(7),(8)

Awareness creation in coordination with Eye Bank among rural population reduces corneal/traumatic/posterior segment causes for blindness.

Rural population survey regarding vision, post-operative followup, early reference with the aid of national blindness control programme can reduce prevalence of blindness among early age group and complications related blindness among elders.

\section{CONCLUSION}

Visual disability due to avoidable causes like cataract and its related complications and refractive error ${ }^{(9)}$ can be reduced by awareness among rural population, effective Eye camp functioning, school health programmes with early referral and treatment. So public health and epidemics have been used in combating blindness and disability. Illiteracy(10) and consanguineous marriages add to early age blindness, which can be reduced by awareness creation with the help of the Eye Bank foundation.

\section{REFERENCES}

[1] Natarajan S. Milestones in blindness prevention in India. Indian J Ophthalmol 2012;60(5):347-8.

[2] Jonas JB, George R, Asokan R, et al. Prevalence \& causes of vision loss in Central \& South Asia 1990-2010. Br J Ophthalmol 2014;98(5):592-8.

[3] Dineen B, Foster A, Faal H. A proposed Rapid methodology to assess the prevalence \& causes of blindness \& visual impairment. Oph-Epidemilol 2006;13(1):31-4.

[4] Naidoo K, Gichuhi S, Basanez MG, et al. Prevalence and causes of vision loss in sub-Saharan Africa: 1990-2010. BJO 2014;98(5):612-8.

[5] Dhake PV, Dole K, Khandekar R, et al. Prevalence \& causes of avoidable blindness \& severe visual impairment in a tribal district of Maharastra, India. Oman J Ophthalmol 2011;4(3):129-34.

[6] Patil S, Gogate P, Vora S, et al. Prevalence, causes of blindness, visual impairment \& cataract surgical service in Sindhdurg district on the western coastal strip of India. IJO 2014;62(2):240-5.

[7] Khanna RC, Marmanula S, Krishnaiah S, et al. Changing Trends in prevalence blindness \& visual impairment in a rural district of India. Systematic observations over a decade. IJO 2012;60(5):492-7.

[8] Neena J, Rachel J, Praveen V, et al. Rapid assessment of avoidable blindness in India. PLoS One 2008;3(8): e2867.

[9] Kyari F, Gudlavalleti MV, Sivsubramaniam S, et al. Prevalence of blindness \& visual impairment in Nigeria: the National Blindness and Visual Impairment Study. Invest Ophthalmol Vis Sci 2009;50(5):2033-9.

[10] Stevens GA, White RA, Flaxman SR, et al. Global prevalence of vision impairment \& blindness: magnitude and temporal trends, 1990-2010. Ophthalmology 2013;120(12):2377-84. 